\section{Editorial: Periódicos, liberdade e verdade}

Os periódicos são o meio oficial do discurso científico. E, já que a ciência se pauta na busca da verdade, tal discurso deve ser livre porque a verdade pode ser inconveniente e nada popular. Tendo isto em mente, no primeiro editorial de 2019, gostaria de tratar da necessidade de se zelar pela liberdade acadêmica e científica, pois as recentes ameaças a professores e pesquisadores não tentam somente fragilizar uma categoria profissional e seu sistema legitimamente aceito de produção do conhecimento, mas coloca também em cheque a busca incessante pela verdade por meio da racionalidade e da investigação séria.

Infelizmente, háum advento de ideias obscurantistas, místicas eirracionais, especialmente na esfera política, cujos gurus transvestidos de youtubers e influenciadores digitais reivindicam, com até certo sucesso, o papel de "intelectuais" dessa nova onda de irracionalismo que invadiu recentemente o país. A posse de tais pseudointelectuais não é o conhecimento técnico nem o reconhecimento científico, mas sim a capacidade de despertar paixões viscerais, muitas delas negativas como ódio, fúria e desprezo, que mobilizam massas de apoiadores cegos por seus vieses de confirmação e por seus estereótipos. Essa massa não se interessa necessariamente pela verdade, ela se guia de fato pela aceitação e pela afirmação da sua posição e, por ser mais numerosa, suas ideias, muitas vezes equivocadas, podem ameaçar qualquer tentativa de discussão racional e sistemática dos problemas nacionais.

A Revista Eletrônica de Ciência Administrativa, até por ter a palavra ciência em sua composição, não poderia deixar de pautar a importância de se ressaltar o papel da investigação científica na compreensão de problemas sociais e organizacionais que tanto permearam os recentes debates nas mídias televisivas e sociais. Para isso, gostaria de ressaltar neste editorial três pontos: 1) o desejo pela verdade científica como objetivo primordial (Popper, 1980), mesmo sabendo que tal verdade opera num campo com interesses em disputa como qualquer outro (Bourdieu, 1975); 2) a necessidade da busca da verdade ser livremente e abertamente criticada como critério de demarcação (Popper, 1980); 3) o papel dos periódicos como peça fundamental na livre disseminação de ideias espaciotemporalmente válidas mesmo que carentes de certeza.

Em relação ao primeiro ponto, cabe a questão mais difícil: o que seria a verdade, ou sendo mais específico, o que seria a verdade científica? Thagard (2007), fortemente se baseando na definição de Goldman (1999), entende por verdadeiras aquelas proposições que intentam descrever a realidade e que, ao mesmo tempo, seu conteúdo se ajusta à realidade. Tal concepção de verdade científica se aproxima muito da doutrina galileana de que a ciência em geral, e o cientista em particular, buscam uma descrição verdadeira do mundo e de qualquer de suas partes, bem como intencionam uma explicação verdadeira dos fatos. E, como aponta Popper (1980), por mais que o cientista aspire a verdade, ele nunca poderá estar certo de que suas
Luciano Rossoni iD,

Editor da RECADM

UniGranRio, Brasil

Irossoni@gmail.com 
descobertas ou afirmações são verdadeiras. Nas palavras de Popper (1980: 146), verdades [científicas] são "conjeturas genuínas - suposições altamente informativas acerca do mundo que embora não sejam verificáveis, podem ser submetidas a severos testes críticos". Em suma, verdades científicas são disposicionais, pois, na verdade, são tentativas sérias de se descobrir a verdade acerca da realidade por meio da contínua aproximação, mesmo que de forma transitória. Isso porque os resultados científicos constituem uma etapa de seu desenvolvimento e são passíveis de serem ultrapassados no decurso de seu progresso (Popper, 1974).

O que é mais contraditório, pelo menos para os leigos, é que a verdade científica se baseia em conjeturas ou suposições acerca da realidade que, por sua vez, sempre a reserva um caráter incerto, já que que nosso conhecimento em dado momento é também incerto ou conjetural. Com efeito, isso afasta a ciência da certeza. Logo, certezas não são verdades, e a busca por certezas é campo aberto para oportunistas, falsos profetas e charlatões, como muito vemos por aí. Certezas remetem ao dogmatismo, não a investigação científica séria. Por mais que sejam sedutoras, elas carecem de respaldo e de fundamentação, já que não passaram pelo crivo de indivíduos que racionalmente julgaram tais dogmas.

Irônico ainda, e que remete ao segundo ponto, é que a objetividade da ciência em se fazer tal julgamento racional está intimamente ligado aos aspectos sociais do método científico. Popper (1974) aponta que tais aspectos envolvem rechaçar as tentativas individuais de busca da verdade frente à cooperação, ao mesmo tempo hostil e amistosa, de críticos cientistas. Daí a ideia do autor de caráter público do método científico: livre, crítico e racionalmente severo. Algo que não ocorre em acepções dogmáticas da realidade, já que sua natureza é inquestionável e fechada.

Cabe ao cientista então, mesmo que convicto da fidedignidade de suas conjunturas, expor-se aos colegas para por em prova as qualidades e a validade de seus sistemas de hipóteses acerca da realidade que se quer instruir. Para tanto, como bem aponta Popper (1974), tais cientistas apresentam suas ideias atendendo a convenções de conteúdo e forma que permitam que elas sejam testadas e criticadas, ao ponto de de serem aceitas ou refutadas nesse tipo de experiência.

Derivado de tais espaços abertos às críticas é que se constitui a objetividade científica no sentido popperiano. Para Popper (1974: 174), "aquilo que chamamos de 'objetividade' científica não é produto da imparcialidade de um cientista tomado individualmente, mas o produto do caráter social ou público do método científico [...]." E, ainda segundo Popper (1974), elas são tão fundamentais, que há uma série de instituições criadas para estimular tal objetividade e crítica. Em especial, no caso que quero destacar aqui, a instituição dos periódicos científicos.

Periódicos científicos, que destaquei como terceiro ponto, têm papel fundamental na disseminação de formas racionais de se apreciar a realidade, em especial a social e organizacional. Como são centrais para a propagação das ideias científicas e, ao mesmo tempo, podem ser alvos fáceis de investidas 
de inquisidores, devem ser protegidos de políticos cujas ideias em nada refletem o espírito de verdade da ciência. Pois, como aponta Popper (1974: 173), "só o poder político, quando usado para reprimir a livre crítica, [...] pode prejudicar o funcionamento dessas instituições, das quais todo progresso, seja ele científico, tecnológico ou político, depende em última instância."

E no caso das ciências sociais e organizacionais, sempre há maior vulnerabilidade de tais ingerências políticas, pois tais políticos, de uma maneira geral, ainda acreditam que a sociedade e as organizações são espaço restrito da performatividade e até da irracionalidade. E, como bem apontou Popper (1974), as ciências sociais devem enfrentar seus problemas práticos com a ajuda de métodos teóricos que, em sua essência, estejam preocupados com a verdade, para, por sua vez, afastar os demônios da irracionalidade. Não que deixemos de fazer isso, mas diante dos desafios atuais, teremos que deixar cada vez mais demarcado o espaço do que é conhecimento de fato do espaço do simples achismo.

Por isso que neste editorial faço um apelo à racionalidade científica, defendendo sua liberdade e de seus cientistas, cuja imensa maioria no país assume o duplo papel de professor-pesquisador. Para tanto, devemos abraçar nossos problemas reais, discutir cada vez mais abertamente nossas ideias, pondo-as em prova. Pois o inimigo do irracionalismo sempre estará presente. Em minha parte, enquanto editor, assumo publicamente o compromisso da RECADM em não se esquivar de temas ácidos, polêmicos e desafiadores, pois a verdade se busca no limite da racionalidade, não do dogmatismo.

\section{Nesta edição}

Nossa primeira edição de 2019 é marcada fortemente pelo conteúdo da inovação e das tecnologias. Alguns dos artigos destacam suas consequências negativas e suas externalidades, alguns destacam suas subjetividades, e outros ainda remetem a como as organizações se estruturam para permitir a inovação e a adequação tecnológica. O fato é que, desde os seus primórdios, o desenvolvimento de organizações e de tecnologias sempre esteve associado, cujo ápice na teoria das organizações remete a belos trabalhos como os da socióloga Joan Woodward e do não menos brilhante Charles Perrow, que muito bem destacaram como a tecnologia era imperativa na definição de estruturas e processos organizacionais. Diante de tal imperativo tecnológico, muito da discussão acerca da inovação organizacional foi desenvolvido desde então, demonstrando como as organizações se reinventam e se adaptam para prosperarem ou, pelo menos, para não perecerem.

Tais tecnologias são tão relevantes que não somente afetam a vida das organizações em si, mas criam também novas formas de se organizar as relações de trabalho, ou até mesmo a relação com o espaço urbano. Tal ponto é destacado no artigo "Precário não é, mas eu acho que é escravo": Análise do Trabalho dos Motoristas da Uber sob o Enfoque da Precarização, de autoria de Robson Gomes André, Rosana Oliveira da Silva e Rejane Prevot Nascimento. Os autores buscaram analisar o trabalho dos motoristas da Uber 
sob o enfoque da precarização, a fim de verificar se ele tem características de um trabalho precário. Os resultados apontam para várias características de um trabalho precário e os motoristas, de alguma forma, o reconhecem como tal, pela renda baixa, exploração e jornada de trabalho excessiva.

O segundo artigo, intitulado Rumo à Economia Circular: Sinergia Existente entre as Definições Conceituais Correlatas e Apropriação para a Literatura Brasileira, das autoras Simone Sehnem e Susana Carla Farias Pereira, tem como objetivo esclarecer as diferenças semânticas e conceituais dos termos: economia circular, economia espiral, cradle to cradle, double loop, closedloop, logística reversa, análise do ciclo de vida, upcycle e simbiose industrial. A contribuição do estudo está alicerçada na categorização da literatura sobre o tema economia circular e seus termos correlatos, assim como na proposição de traduções para termos clássicos da área de operações.

No terceiro artigo, Cultura de Inovação em uma Escola de Negócios: um estudo inspirado pela teoria da prática, o autor Ricardo Pimentel envereda-se em compreender os sentidos da inovação e como constituem a inteligibilidade das práticas que suportam a cultura de inovação em uma escola de negócios. Para tanto, se baseia na teoria da prática de Schatzki, adotando a semiótica fenomenológica como método de análise. Os resultados mostram que os sentidos da inovação estão em constante construção e são perpassados por contradições. A apreensão dessas contradições amplia a compreensão daqueles sentidos, possibilitando o acesso à construção da inteligibilidade das práticas que sustentam a cultura de inovação.

O quarto artigo, Integração Externa e Capacidade de Inovação Organizacional Moderada pelo Nível de Confiança, de autoria de Sidnei Gripa e Luciano Castro de Carvalho, tem como objetivo identificar se a integração de clientes e fornecedores influenciam a capacidade de inovação organizacional. Os resultados indicam que o envolvimento do cliente influencia na capacidade de inovação organizacional, porém o envolvimento do fornecedor, bem como a moderação da confiança nas relações não foram significativas.

Já no quinto artigo, Apoio das Universidades aos Spin-Offs Acadêmicos nas Fases de Early e Later Stage, as autoras Cibele Lopes Souto MaiorCabanne, Xênia L'amour Campos Oliveira e Rivanda Meira Teixeira propõem analisar as formas de apoio concedido pelas universidades aos spinoffs acadêmicos nas fases iniciais e tardias de desenvolvimento. No caso estudado, foi observardo que o apoio fornecido pelas universidades aos spin-offs foi considerado deficiente nas duas fases, já que não foi observado participação ativa da universidade na obtenção de recursos, disponibilização de contatos ou oferta de disciplinas voltadas ao empreendedorismo. O mérito das universidades consistiu na disponibilização das incubadoras e, por meio delas, cursos de capacitação e infraestrutura.

Por fim, em nosso sexto artigo, A Influência da Denominação de Origem na Percepção de Consumidores de Café: Um Estudo com Brasileiros e Franceses, Adriana Dossin, Fernanda Lazzari, Gabriel Sperandio Milan e Tatiana Piccin analisaram por meio de um estudo experimental a utilização 
do selo de denominação de origem em cafés da região do Cerrado Mineiro e seu efeito na percepção de qualidade, confiança, intenção de compra e disposição de preço a pagar de consumidores brasileiros e franceses. Os resultados mostram que o reconhecimento da região certificada influencia as percepções sobre o produto, tanto para os consumidores brasileiros quanto para os consumidores franceses.

Como palavra final, gostaria de frisar alguns projetos da RECADM para 2019. No final do ano que se passou, submetemos propostas de inclusão da revista no Redalyc, no SCOPUS e no Web of Science. Por mais que algumas dessas inclusões em bases e indexadores internacionais sejam cerimoniais, cujo impacto na qualidade do periódico não é necessariamente efetivo, somos avaliados pelo sistema CAPES por fazer parte de tais bases. Não há muita alternativa neste caso a não ser "jogar o jogo". Além disso, em alguns casos, autores usam tais indexadores para definir os periódicos alvos de publicação, o que pode afetar na melhora do nível de submissões dos manuscritos. No ano que se passou, tivemos um volume alto de artigos recebidos, porém as aceitações foram de somente $9 \%$. Número extremamente baixo, ao meu ver, em que a presença em tais bases talvez melhore essa proporção. Somado ao engajamento na inclusão de novos indexadores, estamos incorporando no portal da RECADM novas formas de avaliar as métricas de impacto dos artigos, considerando ferramentas que facilitem a busca e visualização diretamente na página. Provavelmente tais ferramentas já estarão visíveis e operantes no primeiro quadrimestre de 2019. Despeço-me mais uma vez agradecendo o generoso trabalho dos avaliadores, bem como da equipe que dá suporte à RECADM, que facilitam muito a vida do editor.

Um ano de paz e excelente leitura,

\section{Luciano Rossoni}

Editor da RECADM 


\section{Referências}

Bourdieu, P. (1975). The specificity of the scientific field and the social conditions of the progress of reason. Social Science Information, 14(6), 19-47.

Goldman, A. (1999). Knowledge in a Social World. Oxford: Oxford University Press.

Popper, K. R. (1974). A sociedade aberta e seus inimigos (Vol. 2). São Paulo: Universidade de São Paulo.

Popper, K. R. (1980). Três concepções acerca do conhecimento humano. São Paulo: Abril Cultural.

Thagard, P. (2007). Coherence, truth, and the development of scientific knowledge. Philosophy of Science, 74(1), 28-47. 